\title{
Potential for Stem Cells Therapy in Alzheimer's Disease: Do Neurotrophic Factors Play Critical Role?
}

\author{
Parul Bali ${ }^{1,3}$, Debomoy K. Lahiri ${ }^{2}$, Avijit Banik ${ }^{3}$, Bimla Nehru ${ }^{1}$ and Akshay Anand ${ }^{3, *}$
}

\author{
${ }^{I}$ Department of Biophysics, Panjab University, Chandigarh, India $;{ }^{2}$ Department of Psychiatry and of \\ Medical \& Molecular Genetics, Indiana University School of Medicine, Institute of Psychiatry Re- \\ search, Neuroscience Research Center, 320 West 15th Street, Indianapolis, IN-46202, USA; \\ ${ }^{3}$ Neuroscience Research Lab, Department of Neurology, Post Graduate Institute of Medical Education \\ and Research, Chandigarh, India
}

\begin{abstract}
Alzheimer's disease (AD) is one of the common causes of dementia. Despite several decades of serious research in AD there is no standard disease modifying therapy available. Stem cells hold immense potential to regenerate tissue systems and are studied in a number of brain-related disorders. For various untreatable neurodegenerative disorders, such as Alzheimer's disease (AD), amyotrophic lateral sclerosis (ALS) and Parkinson's disease (PD) (current-approved drugs provide only symptomatic relief), stem cell therapy holds a great promise and provides a great research opportunity. Here we review several stem cell transplantation studies with reference to both preclinical and clinical approaches. We focus on different sources of stem cells in a number of animal models and on molecular mechanisms involved in possible treatment of neurodegenerative disorders. The clinical studies reviewed suggest safety efficacy and translational potential of stem cell therapy. The therapeutic outcome of stem cell transplantation has been promising in many studies but no unifying hypothesis exists for an underlying mechanism. Some studies reported paracrine effects exerted by these cells via release of neurotrophic factors, while other studies reported immunomodulatory effects by transplanted cells. There are also reports supporting stem cell transplantation causing endogenous cell proliferation or replacement of diseased cells at the site of degeneration. In animal models of $\mathrm{AD}$, stem cell transplantation is also believed to increase expression of synaptic proteins. A number of stem cell transplantation studies point out great potential for this novel approach in preventing or halting several neurodegenerative diseases. The current challenge is to clearly define the molecular mechanism by which stem cells operate and the extent of actual contribution by the exogenous and/or endogenous cells in the rescue of disease.
\end{abstract}

Keywords: Stem cells, Alzheimer's disease, neurodegeneration, synaptogenesis, differentiation, proliferation, therapeutics, transplantation.

\section{INTRODUCTION: THE POTENTIAL OF STEM CELL IMPLANTATION IN ALZHEIMER'S DISEASE}

A number of neurodegenerative disorders, such as Alzheimer's disease (AD), Amyotrophic lateral sclerosis (ALS) and Parkinson's disease (PD) are untreatable, and they progressively worsen with age, resulting in death. The world Alzheimer Repot 2015 reported over 46 million individuals in the world's population suffer from dementia, and this number is estimated to increase upto 131.5 million by 2050 [1]. Dementia is associated with multiple causes that include alcoholism, AD, stroke, PD and drug/medication intoxication. It is the fifth leading cause of death in the US with age of 65 years or above. In 2015 AD prevalence in USA was estimated to be close to 5.3 million, and this is expected to rise up to 11 to 16 million in 2050 [2]. In India, the number of individuals which are suffering from $\mathrm{AD}$ and other dementia is estimated to be approximate 3.7 million and this number is expected to double by the year 2030 [3].

*Address correspondence to this author at the Neuroscience Research Lab, Department of Neurology, Post Graduate Institute of Medical Education and Research, Chandigarh, India; Tel: +91 9914209090;

E-mail: akshay1anand@rediffmail.com
The most common form of dementia, Alzheimer's disease, is characterized by different stages of cognitive and functional impairment. Patients suffering from $\mathrm{AD}$ lose autonomy in their daily normal activities, and this progressively deteriorates with age. In 1901, Alois Alzheimer, a German psychiatrist, diagnosed a 51 year-old woman with a condition he called "amnestic writing disorder" [4]. Her psychosocial abnormalities included aphasia and memory impairment. Later, in 1910 when Alzheimer's supervisor published his book Psychiatrie, he reported this case and mentioned this condition as Alzheimer's disease (AD) [4]. Since then, extensive research has progressed worldwide to understand several aspects of the disease, ranging from its pathology, disease onset, prevalence, diagnosis and treatment in various cellular, pre-clinical and clinical studies. Currently, AD pathophysiology is based on several important hypotheses i.e., including the cholinergic hypothesis, protein misfolding, and amyloid cascade hypotheses [5-7].

The hippocampus plays a significant role in memory encoding and retrieval. Hippocampus is the first region of the brain to be affected in AD. Injury to brain tissue has not been seriously considered for treatment by cell replacement 
strategies as compared to the other organs e.g. skin and liver tissues. Earlier, neuroanatomists considered that the nervous system is incapable of regeneration. In 1962 Joseph Altman provided the first evidence of neurogenesis in the cerebral cortex and later, in 1963 he showed the occurrence of neurogenesis in the dentate gyrus of rat and cat hippocampus [8]. In some animals, neuronal precursors originate from the subventricular zone (SVZ) to the main olfactory bulb via specialized migratory route known as the rostral migratory stream (RMS). More recently, various strategies are being employed to activate these lesser population of stem cells by various methods [9]. Currently available FDA-approved drugs for $\mathrm{AD}$ provide symptomatic relief to the patients without alleviating elusive disease pathology., Alternative strategies such as herbal remedies [10-12] and cell based therapies $[13,14]$ are being tested in preclinical settings with the hope of halting disease progression. The underlying mechanism is either replacement of degenerating neurons or exerting neuroprotection by the paracrine effect of transplanted cells by the secretion of neurotrophic factors (Fig. 1) [15]. The efficacy of stem cells has been studied in various pre-clinical studies by transplanting these cells into the disease-specific animal models. However, there is a gap of knowledge describing the underlying molecular mechanisms involved in the rescue of disease by transplanted cells.

\section{PATHOPHYSIOLOGICAL FEATURES IN ALZ- HEIMER'S DISEASE}

Several animal studies and human brain biopsies have revealed the pathological hallmarks of $\mathrm{AD}$, including extracellular amyloid- $\beta(\mathrm{A} \beta)$ plaque deposits and formation of intracellular neurofibrillary tangles (NFT). NFT are misfolded structures produced by aberrant phosphorylation of microtubule-stabilizing tau proteins. The process of $A \beta$ formation is known to play a significant role in AD etiology [16]. Amyloid plaques trigger a pathological cascade resulting in neurofibrillary tangles and neuroinflammation causing neuritic dysfunction, which ultimately leads to neuronal death. In AD patients, excessive accumulation of Amyloid plaques is likely to be due to dysregulation of activity of $\beta$ site Amyloid Precursor Protein-Cleaving Enzyme 1 (BACE1). BACE1 gives rise to $\mathrm{A} \beta$ from the membranespanning $A \beta$ precursor protein (APP). This is the rate limiting step of $A \beta$ production. This cleavage occurs at the APP $\mathrm{N}$-terminus to form soluble APP $\beta$, and the c-terminus is further cleaved by $\gamma$-secretase complex, which yields $A \beta 40 / 42$ [17]. These $A \beta$ fragments thus generated aggregate to form amyloid fibrils. A $\beta 40$ (with 40 amino acid residue) is the predominant form but $\mathrm{A} \beta 42$ (with 42 residues) is more fibrillogenic than its shorter sibling and is involved in disease pathology.

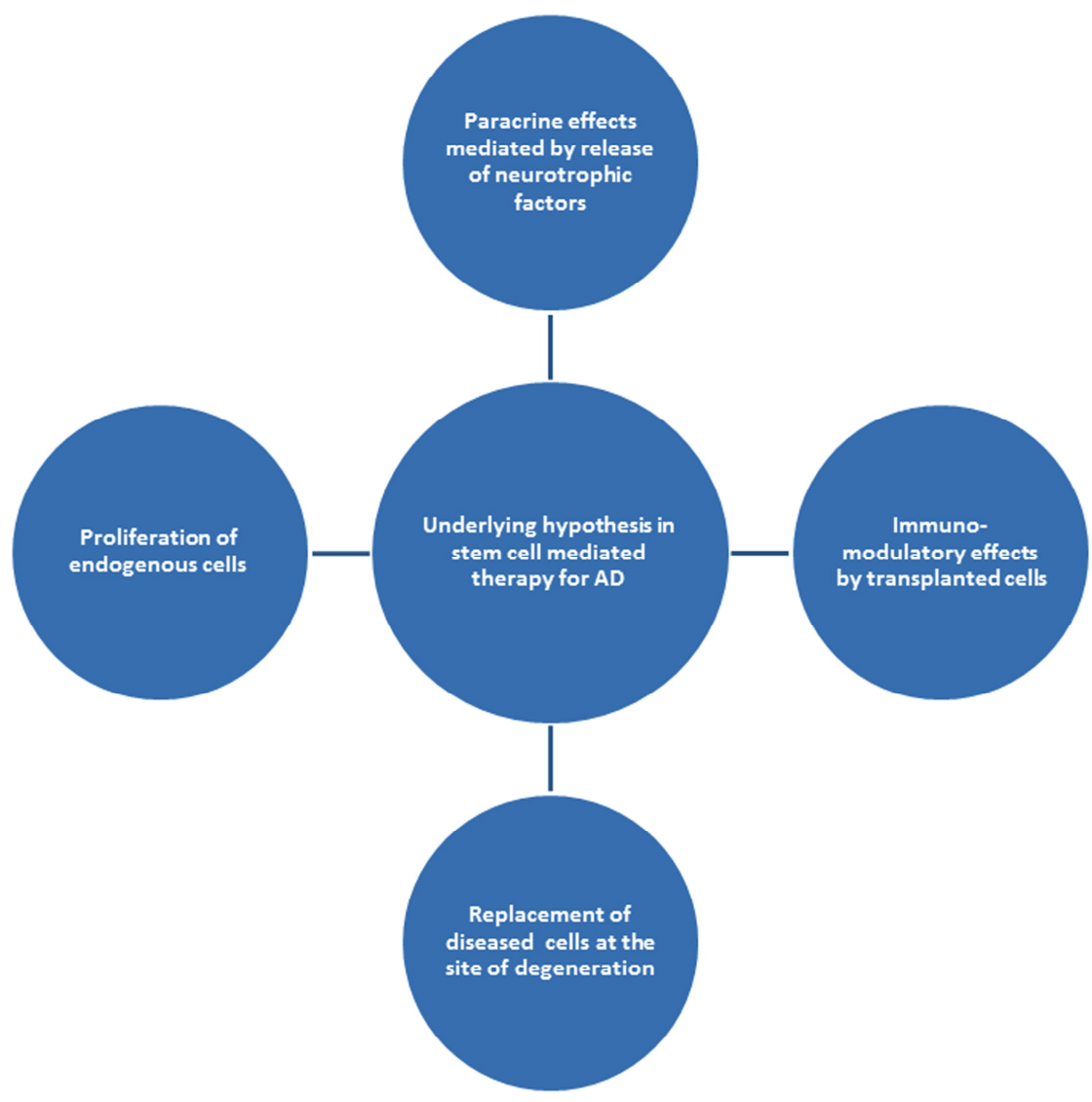

Fig. (1). Outline for underlying mechanism in stem cell mediated reversal of AD pathology. Some underlying hypothesis may explain functional improvements in subjects of stem cell transplantation in AD. However, current experiments point to four possible explanations. A) Paracrine effects from release of neurotrophic factors by transplanted cells. B) Immunomodulatory effects by transplanted cells. C) Replacement of diseased cells by transplanted cells. D) Proliferation of endogenous cells. It is likely that all four processes operate in interaction to produce any final salutary effects. 
There are several environmental factors that cause epigenetic changes in healthy individuals. It plays a significant role in regulating the gene expression through direct modification of DNA and histone protein modification leading to genetic dysregulation thereby causing various disease pathologies. In AD, amyloid fibril-induced neuroinflammation is believed to increase expression of epigenetic factors such as. methyl-CpG-binding protein 2 and histone Deacetylase 2 and their interaction further suppresses the expression of synaptic protein leading to amyloid induced memory deficiency [18].

Tau is an intracellular microtubule associated protein that plays an essential role in microtubule stabilization. Abnormal phosphorylation of tau leads to microtubule disruption. The formation of neurofibrillary tangles may be triggered by amyloid plaque. Likewise, another cholinergic hypothesis postulates a reduction in neurotransmitter acetylcholine in the AD patients [19] as the primary cause of AD. Besides amyloid plaque deposition and neurofibrillary tangle formation, vascular dysfunction also appears in AD pathophysiology.

Both genetic and environmental factors contribute to etiology of AD. Genetic factors linked to autosomal dominant inherited mutations include presenilin 1, presenilin 2, amyloid precursor protein and enzymes that are involved in amyloid processing such as BACE1. These genetic forms, also called familial AD (FAD) contribute marginally towards prevalence (no more than $5 \%$ of $\mathrm{AD}$ cases [20]), whereas most cases are sporadic, with an unknown cause. The E4 variant of apoE is largely known as a major genetic risk factor for the late onset of AD [21]. Studies suggest that there are some interactions with amyloid to cause this dramatic effect [22]. Some studies also propose that sporadic cases are the result of various environmental and epigenetic factors which lead to an etiology based upon "Latent Early-life Associated Regulation" (LEARn). LEARn describes effects resulting from exposure of stressors in early life e.g. nutritional imbalance, toxic metals (such as lead) and other stressors, which induce epigenetic alterations on disease associated gene chromatin or histones [23]. These changes remain latent as (de)methylation of promoter or chromatin modifications by (de)acetylation, (de)methylation and (de)phosphorylation. Upon one or more additional hits in the later life, expression of modified gene(s) alters sufficiently to induce pathology.

\section{CELL TYPE CONSIDERATIONS FOR DISEASE MODIFYING THERAPIES}

The requirement of a suitable cell type with particular characteristics for specific disease types is needed for proper and effective cell transplantation. Stem cells from several tissues such as bone marrow and umbilical cord blood are well characterized for their proliferation and differentiation properties and can be an optimum source for transplantation $[24,25]$. Current strategies emphasize culturing of isolated cells in an optimum medium with suitable nutrient environment to obtain the desired disease phenotype. The microenvironment also provides suitable niche for selective expression of desirable markers to trigger these cells for a specialized cell type [26, 27]. Long-term culture and characteriza- tion of primary neurons isolated from rodent and human fetal tissue is essential for undertaking comparative studies. Abundant tau and amyloid- $\beta$ production in human brain cultures provides a powerful cellular model for AD. In a recent study Ray et al provide a well-characterized methodology for fetal human primary brain cell culture, which is useful to test the therapeutic efficacy of drugs targeting AD [28]. Cultures of induced pluripotent stem cell (iPSC) generated from fibroblasts of familial AD (FAD) patients with presenilin 1 and presenilin 2 mutations were characterized after acquiring neuronal lineage [29]. Apart from increased A $\beta 42$ expression, the iPSC model also showed variable drug response and alleviation of stress induced response by docosahexaenoic acid (DHA) treatment [30]. Likewise, RNA silencing has also been used in this cellular model. Therapeutic strategies derived, therefrom focus on targeting production of $A \beta$ by identifying key molecular regulators of BACE1 expression. The authors have also elucidated the role of human micro-RNA (miR)-339-5p which negatively modulates BACE1 in primary human brain cultures, and expression of miR-339-5p is reduced in AD patients [31].

\section{PRE-CLINICAL STUDIES TO PROBE REGENERA- TIVE POTENTIAL OF STEM CELLS}

At present, there are no consensus measures to accurately diagnose and monitor progression of AD [32]. This significantly hinders effective treatments against AD. To study AD pathologies and its targets, different animal models of AD have been established and tested in preclinical settings. These model systems range from laboratory animals like zebrafish, murid rodents and nonhuman primates to model invertebrates such as Drosophila and $C$ elegans. Among these, rats and mice are widely used, and their transgenic counterparts are the most-established system to evaluate disease pathophysiology as well as effective treatment strategies. Several strategies have been adopted to establish AD like pathologies and induced memory impairment in these models [33]. These include predetermined brain injury, neurotoxin induced cell loss in brain and intra-cerebroventricular injection of $\mathrm{A} \beta$ peptides [34].

Currently used treatments for AD includes blocking neurotransmitter degradation, which provide temporary symptomatic relief without alleviating the pathophysiological burden of the disease. Therefore, alternative cell based studies for transplantation have been carried out in the belief that either these cells replace degenerating neurons or secrete trophic factors that provide a protective environment to the endogenous cells. Various neurotrophic factors are secreted by the cells to modulate the synaptic functioning in brain. In particular, BDNF is synthesized by neurons and highly expressed in cortex and hippocampus; these regions are crucial for learning and memory in brain [37].

The animal models associated with $A \beta$-induced memory loss have been widely studied in understanding pathophysiology of AD and testing therapeutic efficacy of various drug targets. Prakash et al. use intracerebroventricular (ICV) injection of $\mathrm{A} \beta$ to study the role of pioglitazone, a peroxisome proliferator-activated receptor- $\gamma$ (PPAR- $\gamma$ ) agonist, on neurotrophic factor BDNF in a rat model of $\mathrm{AD}$ with neuroinflammation. A $\beta$-injured animals showed significant impair- 
ment in memory as well as reduced levels of BDNF, which were reversed by administration of pioglitazone [38]. Tang et al. demonstrated fibrillar $A \beta 40$ induced neurotoxicity in rat hippocampus, characterized by congo red plaques and degenerating neurons at the site of injection. This pathological outcome was supported by impaired cognitive performance in the rats, tested in Morris water maze. Further, they have used this model to validate cell replacement efficacy of neural precursor cells derived from human embryonic stem cells. The neural precursor cells are partially differentiated, as these cells are more precisely committed to their lineage [39]. The transplanted cells were found to ameliorate $A \beta$ induced cognitive impairment in these rats and further survived, integrated and differentiated into GFAP and NF-200 positive neuronal cells after 16 weeks of transplantation [40].

Blurton-Jones et al. explored the role of neural stem cell transplantation in reversal of memory impairment. To study the effect of neural stem cells (NSCs) in AD pathology and cognitive functions, these cells were transplanted into aged triple transgenic mice that express mutant presenilin, tau and APP with aggressive A $\beta$ load. Remarkably, transplanted NSCs were found to ameliorate loss in spatial learning and memory without altering $A \beta$ and tau pathologies. Further, these cells increased synaptic density in diseased brain, which was assisted by BDNF. Loss of function studies have revealed that NSCs exert regenerative effects mediated by BDNF. It was further found that restoration of memory loss occurred when recombinant BDNF was additionally supplemented [15]. The same group recently reported that when these NSCs were genetically engineered to stably release the A $\beta$ degrading enzyme neprilysin, they could augment synaptic plasticity as well as ameliorate underlying $A \beta$ pathology in triple transgenic mice [41]. Ealier, Neuralstem, Inc. had announced the first data on neural stem cells transplantation studies in an animal model of AD. Their group reported that HK532: IGF1 (NSI-532.IGF) cells ameliorate spatial learning deficits and improved memory in AD mice. To generate human insulin-like growth factor 1 (IGF-1), a cortical neural stem cell line was engineered. IGF-1 cells also impart a wide-range of neuroprotective properties [42]. Notably, the cells, which were administered in the peri-hippocampal region showed survival up to ten weeks. Also, mice with stem cell transplantation performed better than did control mice at fourteen weeks after the surgery. It would be reasonable to conclude that such preliminary studies point toward a potentially feasible therapeutic approach to treat $A D$ in the future and that the therapeutic effect of stem cells upon transplantation into the brain is supported by a combination of approaches and largely mediated or at least significantly influenced by paracrine effects.

\section{IMMUNOMODULATORY EFFECTS OF STEM CELLS TARGETING AD PATHOLOGY}

Reports also suggest that transplanted stem cells exerts some immunomodulatory response at the site of injury, leading to release of cytokines that further target the underlying AD pathology. Jin et al. highlighted the phenomenon of crosstalk between transplanted cells and endogenous neuroproliferative cells by the transplantation of neural precursor cells (NPC) in focal cerebral ischemia of rat brain. In their earlier study they found reduced infarct volume and improved behavioral outcomes upon transplantation of NPC in middle cerebral artery occlusion model of rat. In a more recent study neurogenesis was shown by increase in BrdU labeling and expression of neuronal migration protein doublecortin in the ipsilateral subventricular zone (SVZ) whereas not in contralateral SVZ or subgranular zone (SGZ) in young and aged rats [43]. In another study, authors have administered umbilical cord blood-derived mesenchymal stem cells (UCB-MSC) in double transgenic mice of PS1 and APP that substantially ameliorated loss of spatial learning and memory by microglia activation. Further, the expression of $A \beta$ peptide, hyperphosphorylation of tau and $\beta$ secretase activity were reduced significantly. This neuroprotective effect by UCB-MSC involved modulation of neuroinflammation due to reduction in pro-inflammatory and increase in anti-inflammatory cytokines, induced by microglia activation [44]. These findings suggest that UCB-MSC acts as a therapeutic agent to ameliorate decline in cognitive functions in AD model mice.

Besides amyloid plaque deposition and neurofibrillary tangle formation, vascular dysfunction also contributes to the Alzheimer's Disease pathophysiology. Vascular endothelial growth factor (VEGF) is also implicated in AD related neurodegeneration. Therefore Garcia et al used the strategy of providing VEGF by transplantation of overexpressing bone marrow derived mesenchymal cells into the lateral ventricles of brain using stereotaxic surgery in double transgenic mouse model with $\mathrm{APP}_{\mathrm{SWE}} / \mathrm{PS}_{\mathrm{dE}}$ mutations [45]. Behavioral and molecular parameters were assessed for vascularization and amyloid plaque deposition. Outcomes included reduced behavioral deficit and amyloid deposition besides inducing favored neovascularization. Yang et al. have used cell based approach and transplanted differentiated neuron like cells in APP/PS1 transgenic mice. They used human mesenchymal stem cells derived from Wharton's jelly of umbilical cord and transdifferentiated into neuron-like cells (HUMSC-NCs) by tricyclodecan-9-yl-xanthogenate (D609). Transplantation of HUMSC-NCs in a transgenic APP/PS1 mouse model significantly reduced $\mathrm{A} \beta$ load and improved cognitive functions via increase in microglial activation and expression of the neprilysin (NEP) and A $\beta$ degrading enzymes insulin-degrading enzyme (IDE). Expression of proinflammatory markers associated with the modulation of M2-like microglia (a type of microglia classified based on its mannose receptor and its activation by IL-4 cytokine [46]) activation was reduced whereas expression of antiinflammatory markers, such as interleukin-4 (IL4), was found to be increased [47]. Mesenchymal stem cells derived from bone marrow of male Sprague-Dawley rats were transplanted in female rats by tail vein injection [48]. BM-MSCs were found to increase expression of nestin andcholine acetyltransferase positive cells at the injured area in the brain. Notably, these cells displayed a reduction in amyloid plaques in hippocampus.

Thus, bone marrow cells bring about their therapeutic effect by mechanisms involving anti-apoptotic activity, immunomodulation, and neurogenic properties. Furthermore, neurogenesis in the subgranular zone of dentate gyrus may act as an endogenous repair mechanism in AD via $W n t$ pathway in amyloid-related neurodegeneration associated with AD. Workers also investigated the role of mesenchymal stem 
cells on hippocampal neurogenesis by co-culturing with the amyloid treated neural progenitor cells. Mesenchymal stem cells treatment to NPC significantly enhances the expression of GFAP, Ki67, HuD c, SOX2, and Nestin. Transplantation of these mesenchymal stem cells in $A \beta$-treated animals increases BrdU and $\mathrm{HuD}$ double positive cells in hippocampus at 2 and 4 weeks as compared to control and $\mathrm{A} \beta$-treated alone animals [49]. This shows that MSC administration caused hippocampal neurogenesis and increased differentiation of NPC, which is modulated by Wnt pathway. This may provide and may provide a far better therapeutic approach for treating $\mathrm{AD}$ patients than what is offered by anticholinesterase drugs. Zhang et al realized that neural stem cell transplantation could provide a better approach for the therapeutic treatment of $\mathrm{AD}$ and hypothesized that the transplantation of NSC would ameliorate cognitive impairment by increased expression of synaptic protein. Therefore, they isolated NSC from mouse embryo at embryonic day 14 and transplanted these in both hippocampi of APP/PS1 transgenic mice. Indeed, there was enhancement in cognitive functions analyzed by better spatial learning and memory after $8^{\text {th }}$ weeks of transplantation as compared to the control group. Further, the expression of synaptophysin (SYN) and GAP-43 were found to be increased significantly. Hence, these results suggest that NPC induced cognitive improvement possibly by formation of new neural circuits [50].

Studies have also been carried out to mobilize the quiescent bone marrow stem cell population into the peripheral blood by using stimulating factors. Prakash et al evaluated the effect of granulocyte colony stimulating factor (GCSF) in $\mathrm{A} \beta$ induced memory loss in male adult Wistar rats, and they found significant escalation in behavioral performance after GCSF elevated the progenitor population and CD34 positive cells in the brain affecting neurogenesis [51]. Shetty et al demonstrated the efficacy of mesenchymal stem cells (MSCs) derived from umbilical cord tissue in a Parkinson disease model [52]. They have studied the comparative therapeutic efficacy of MSCs from umbilical tissue and bone marrow as well as efficacy of undifferentiated versus differentiated cells in their model and found better efficacy of differentiated MSCs into dopaminergic phenotype when transplanted. As mesenchymal stem cells lack immunomodulatory activity, these cells provide a novel cellular approach to treat such neurological disorders. Several sources of stem cells in combination with multiple approaches tested in preclinical AD models are further discussed in Table $\mathbf{1 .}$

\section{POTENTIAL ADVERSE EFFECTS STEM CELL THERAPY}

Niche provides the regulatory molecules and suitable physicochemical environment to facilitate the cells to behave in a particular fashion [53]. These cells are exploited for therapeutic purposes, by isolating them from their niche which can pose some unexpected or undesirable outcomes such as tumorigenicity, which has a major concern. Very few studies have reported the potential adverse effect of these stem cells upon transplantation. In one of the study, authors evaluated the long term safety efficacy of 253G1-NSs (neural stem cells). The 253G1-NSs were transplanted to treat spinal cord injury (SCI) in SCID-NOD mice. These transplanted cells were found to have temporary improvement of motor function assessed by rota rod experiment for upto 47 days of post transplantation; however, this was followed by gradual deterioration in motor functioning [54]. It has also been shown to be involved in enhanced proliferation of grafted cells and tumor formation. The proportion of nestin positive cells have been found to be increased from 47 days and 103 post-transplantation which suggests tumor formation in the long term by the grafted cells. In an 18-years old patient with spinal cord injury at T10-T11, an olfactory mucosal cells were transplanted after three years This ledled to severe back pain and paraplegia after 8 years. Further imaging revealed a mass formation of an intramedullary spinal cord [55].

The Yamanaka study of induced pluripotent stem cells opens a big window for untreatable diseases [56] as well as for stem cell clinical trials; even though the use of iPSCs also carries a risk for tumors formation. As the generation of iPSCs involve retroviral transduction by the factors i.e. Oct3/4, Sox2, Klf4 and c-Myc [57]. The retroviral transduction of c-Myc is believe to increase a risk for tumorigenicity, hindering its clinical application. Further the approach has also shown elimination of the c-Myc factor for iPSC generation, which is relatively safer than the earlier approach.

Therefore, an evaluation of safety efficacy of stem cells would provide us better therapeutic approach and its clinical application [58, 59].

\section{THE PUTATIVE LINK OF BDNF AND CREB BE- HIND STEM CELL MEDIATED REGENERATION}

In brain BDNF and CREB (cAMP response elementbinding protein) are believed to play a major role in complex memory formation, consolidation and retention [60-62]. It is also reported in both in-vivo and in-vitro studies that $\mathrm{A} \beta$ induced toxicity leads to downregulation of BDNF and its major regulatory molecule CREB. Hota et al studied the phosphorylation of CREB to investigate the molecular mechanism of bacoside action, as its administration in hypobaric hypoxia induced in rat model, increased learning ability and ameliorated cognitive dysfunction [63]. Tota et al. investigated the effect of angiotensin II on spatial memory and BDNF expression in Sprague-Dawley male rats. Spatial memory was found to be reduced when evaluated by Morris water maze after angiotensin ICV administration and no change was observed in BDNF expression [64]. In an invitro study, Sharma et al have investigated the role of CREB binding protein (CREB-BP) in neuronal differentiation. Their deletion construct $\mathrm{p}$-CREBBP were transfected into NT2 cells and expression profile for neuronal genes i.e. SHH, Wnt, Notch and their mutant counterparts were evaluated. Defects in neuronal differentiation due to aberrant interaction of CREB-BP with their transcriptional regulatory proteins were investigated by CHIP-PCR and coimmunoprecipitation. Cells that are lacking in CREB, BROMO and HAT domains were found to show more proliferation and less differentiation whereas cells expressing CREBBP showed less proliferation and more differentiation [65]. In 2009, Verma et al suggested the role of dichlorvos in memory impairment by muscarinic receptor induced signal transduction and phosphorylation of CREB. Dichlorvos belongs to the organophosphate compounds which are widely 
Table 1. Preclinical Alzheimer's studies of stem cell transplantation

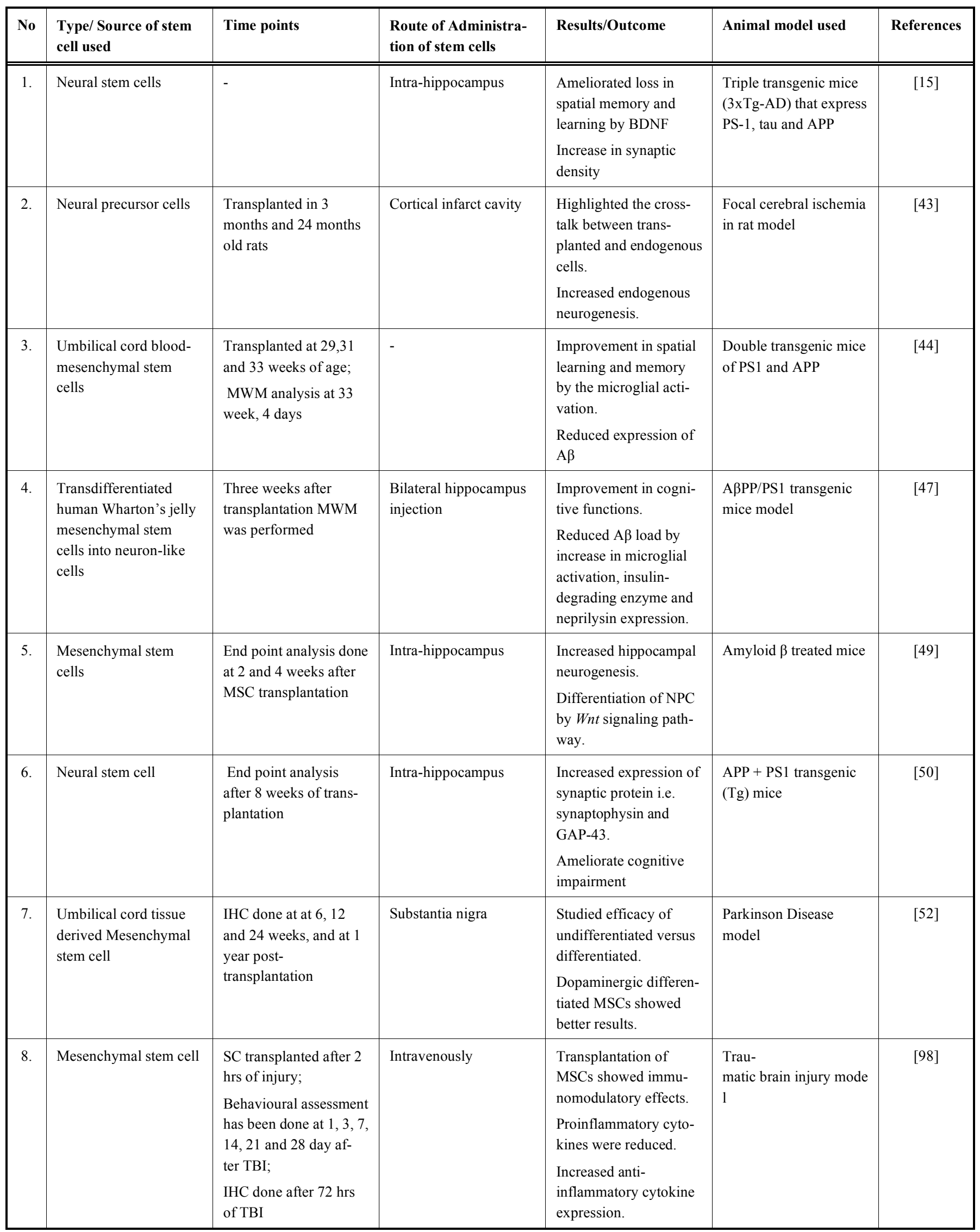


(Table 1)......

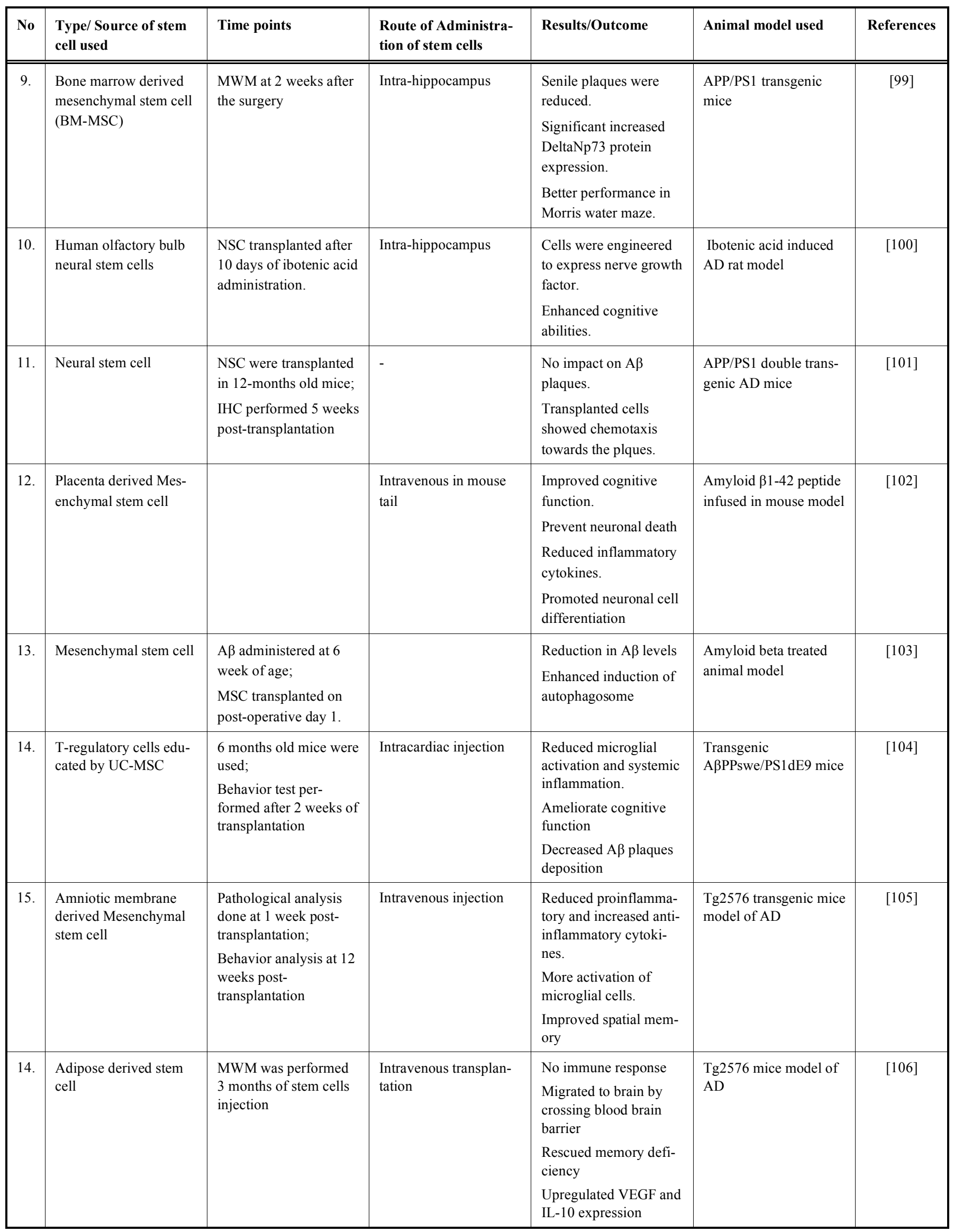


(Table 1)......

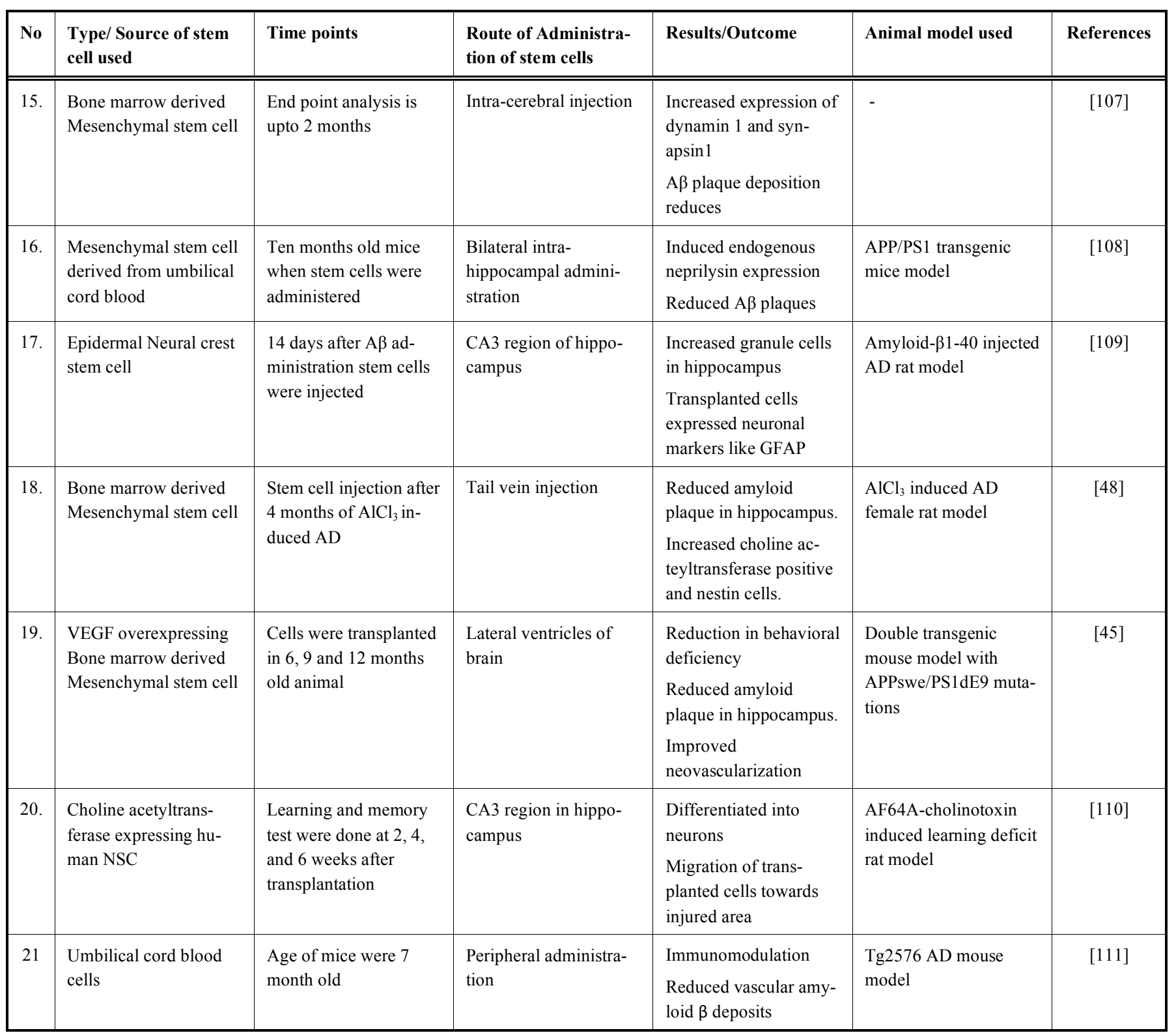

used to as insecticide which may act as cholinesterase inhibitor [66]. Low doses of dichlorvos impaired the signal transduction linked to the adenylyl cyclase pathway and reduced CREB phosphorylation, leading to neurobehavioral impairment [67].

Neurotrophic factors such as BDNF, NGF and GDNF, which have been earlier shown to rescue hypoxia induced ischemic rat brain upon intravenous transplantation of UCB cells, indicates an intrinsic role for neurotrophic factors, rather than direct differentiation, being significant in stem cell mediated recovery [68]. It is pertinent to note that the role of BDNF has been well described in AD literature. BDNF levels are decreased when compared to healthy controls in the postmortem brains of AD patients [69-71]. Mature BDNF and its mRNA expression have also been shown to be confined to hippocampus and parietal cortex region of the brain [72-74]. BDNF is believed to exert neuroprotective effect in several neurodegenerative diseases. This may include pathologies characterized by $\mathrm{A} \beta$-induced neuronal cell death. Several studies have shown the complete reversal of neuroprotective effects driven by BDNF in neuronal culture death induced by $A \beta$ in specific and dose-dependent manner [75-80]. BDNF induced neuroprotective effect has shown incorporation of the $\operatorname{Trk} \beta$ receptor [76]. Moreover, specific A $\beta 42$ induced neuronal cell death has been shown to be reversed by BDNF, in addition to other neurotrophins like IGF-1, GDNF [75].

Since CREB is a DNA binding protein and acts as a transcription factor for several genes, including $c$-fos, tyrosine hydroxylase, several neuronal peptides, and, importantly, neurotrophin BDNF, it is possible that an association exists between the role of BDNF expression and its regulation by CREB in rescuing learning and memory deficits [81, 82]. The function of CREB in the formation of spatial memory; 
conversion of this memory into long term memory and in neuronal plasticity is well documented [83]. It is well known that gene expression has a major role in memory consolidation as well as long term potentiation [83, 84]. These expression profiles are possibly activated through CREB and involvement of $\mathrm{Ca}^{++}$, protein kinase A (PKA) and by the activation of cAMP, but need additional studies [85-87]. The activated PKA would phosphorylate CREB protein which further regulates gene expression of several proteins $[86,88$, 89]. Recently, Suzuki et al. have shown the effect of CREB on both short as well as long term memory. They have reported the increase in long term memory (LTM) as well as long term potential in hippocampus CA1 region in gain-of function CREB mice in which mice express dominant active CREB protein. In addition they reported short term memory improvement in response to fear conditioning and spatial clues, which was related with enhanced BDNF levels in these mice. Therefore, up-regulation of BDNF and CREB expression may mutually trigger enhancement of LTM and STM, suggesting that CREB mediated BDNF expression plays intrinsic role in memory consolidation and retrieval. (Fig. 2) [90].

\section{CLINICAL STUDIES FOR TREATING NEURODE- GENERATIVE DISORDERS:}

Although a number of pre-clinical studies have been launched, very few clinical studies have been carried out so far. Venkataramana et al suggested the safety and effective- ness of autologous bone-marrow derived mesenchymal stem cells when transplanted unilaterally in PD patients. Notably, no adverse effects of these stem cells were seen, paving the way for additional studies in future [91]. In 2012, human retinal stem cells were used to treat PD patients. Authors isolated human retinal stem cells from retinal pigmented epithelium tissue from post-mortem eyes and cultured invitro to differentiate into dopaminergic neurons. These cells were then transplanted by stereotaxic operation into the postcommissural putamen of 12 PD patients. Interestingly, PET analysis showed a trend of increased dopamine release during the 6 month study [92]. In a current study of a phase I open-label clinical trial, authors evaluated the safety efficacy of intrathecal and intravenous transplantation of autologous bone marrow cells in children with cerebral palsy. Eighteen children with cerebral palsy who had transplantation were evaluated for motor and cognitive functions and MRI was done after the sixth month showing it was a safe procedure [93].

There are very few reports registered at www.clinicaltrials.gov of stem cells transplantation in $\mathrm{AD}$ patients, and their outcomes are largely unavailable. In 2011 Medipost Co Ltd. completed an open level, phase I safety and efficacy trial on Korean AD patients, but they did not post their outcome measures. Human umbilical cord blood derived MSCs (UCB-MSCs) were transplanted in AD patients at two different doses ( 3 million and 6 million) and endpoint analysis was measured by ADAS-cog scoring, PET

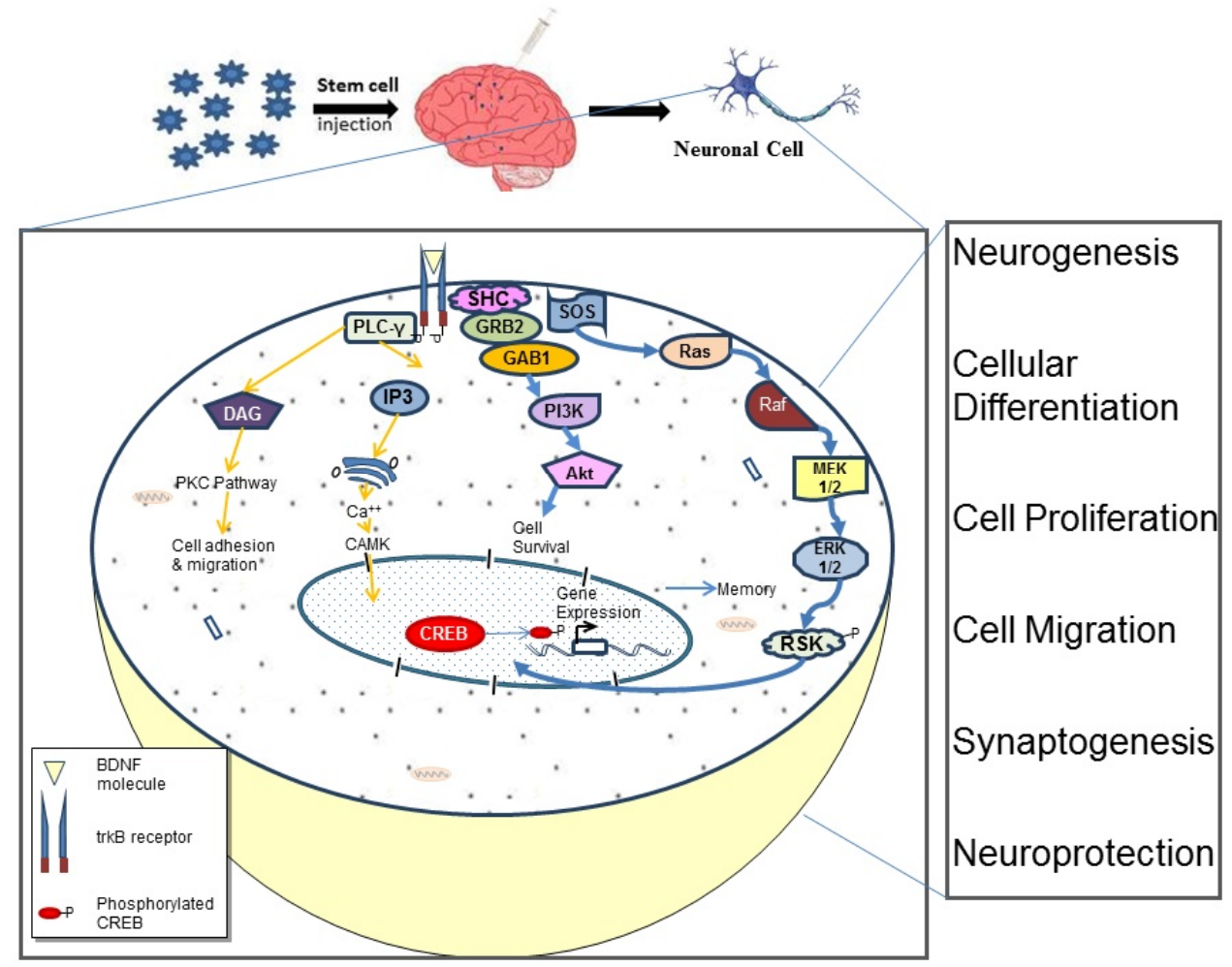

Fig. (2). Schematic showing the plausible mechanism behind stem cell mediated cognitive improvement in Alzheimer's disease. We propose that the therapeutic effect of stem cells upon transplantation into the brain is largely mediated by the paracrine effects. The increase in neurotrophic factors, such as e BDNF, results in increased CREB phosphorylation which in turn activates the genes that regulate cognitive functions and memory by involving one or other phenomena, such as e neuroprotection, cell proliferation, differentiation, cell migration, synaptogenesis and neurogenesis. 
imaging and $\mathrm{A} \beta$ and tau levels in CSF [94]. Another group in China is currently recruiting AD patients in phase I/II trial in a similar study design with 30 probable participants, where patients are intravenously administered with 20 million human UCB-MSCs [95]. Medipost Co Ltd. has recently started a double blinded, placebo controlled, phase I/IIa trial in Korea where patients with mild to moderate $\mathrm{AD}$ will be subjected to repeated intraventricular administrations of UCBMSCs and will be evaluated 24 weeks after first dose of transplantation [96].

\section{CONCLUSION}

Stem cells have promising translational significance, evident by emrging scientific data showing therapeutic benefits in several neurodegenerative disorders. The intrinsic pathways through which these cells exert their therapeutic effects still remain a challenge requiring thorough investigation. There are several studies describing the underlying pathways ranging from proliferation, differentiation, immunomodulation to cell replacement and paracrine effects at the site of neurodegeneration. Pre-clinical studies have shown variable effects by using different types and sources of stem cells. Several studies explain this on the basis of paracrine effects either mediated by neurotrophic factors orendogenous cell proliferation. In animal models of $\mathrm{AD}$, stem cell transplantation has been shown toincrease of synaptic protein marker expression. Transplantation of mesenchymal stem cells have shown decrease in $A \beta$ load due to microglial expression and escalation of $A \beta$ degrading enzymes. A combinatorial approach, wherein stem cells are tagged with neurotransmitters or $\mathrm{A} \beta$ modifying enzymes may exhibit a substantial therapeutic outcome in AD. There is also insufficient literature to explain the actual relative contributions of exogenous cells and endogenous cells towards rescue of function after stem cell transplantation. There is absence of comparative studies involving different sources and types of stem cells i.e. undifferentiated versus differentiated cells in animal models of AD. Nevertheless, a few clinical studies have paved the way for clinical translation but such innovative treatments also carry substantial risk for tumor formation[55]. A thorough investigation is needed on the sources, types, stages, doses and routes of stem cell transplantation in AD model to validate their optimum therapeutic outcome. Moreover, the different stages of $\mathrm{AD}$ progression and other related pathologies may play a critical role in the outcome of the cell transplantation. Hence understanding the etiology of $\mathrm{AD}$ and its other pathologies is of paramount significance for successful clinical translation of stem cell related therapies [97].

\section{LIST OF ABBREVIATIONS}

\begin{tabular}{|c|c|c|}
\hline $\mathrm{AD}$ & $=$ & Alzheimer's disease \\
\hline APP & $=$ & $\mathrm{A} \beta$ precursor protein \\
\hline $\mathrm{A} \beta$ & $=$ & Amyloid Beta \\
\hline BACE1 & $=$ & $\begin{array}{l}\beta \text {-Site Amyloid Precursor Protein-Cleaving } \\
\text { Enzyme } 1\end{array}$ \\
\hline BDNF & $=$ & Brain derived neurotrophic growth factor \\
\hline BM-MSCs & $=$ & $\begin{array}{l}\text { Bone-marrow derived mesenchymal stem } \\
\text { cells }\end{array}$ \\
\hline
\end{tabular}

\begin{tabular}{|c|c|c|}
\hline Brdu & $=$ & Bromodeoxyuridine \\
\hline CHIP & $=$ & Chromatin Immunoprecipitation \\
\hline CREB & $=$ & cAMP response element-binding protein \\
\hline CREBBP & $=$ & CREB binding protein \\
\hline DHA & $=$ & Docosahexaenoic acid \\
\hline FAD & $=$ & Familial Alzheimer's Disease \\
\hline GCSF & $=$ & Granulocyte colony stimulating factor \\
\hline GFAP & $=$ & Glial fibrillary acidic protein \\
\hline $\mathrm{ICV}$ & $=$ & Intracerebroventricular \\
\hline IDE & $=$ & Insulin-degrading enzyme \\
\hline $\mathrm{IHC}$ & $=$ & $\begin{array}{l}\text { Immunohistochemistry iPSC-Induced } \\
\text { pluripotent stem cells }\end{array}$ \\
\hline LTM & $=$ & Long term memory \\
\hline MRI & $=$ & Magnetic resonance imaging \\
\hline NEP & $=$ & Neprilysin \\
\hline NFT & $=$ & Neurofibrillary tangles \\
\hline NPC & $=$ & Neural precursor cells \\
\hline NPC & $=$ & Neural progenitor cells \\
\hline $\mathrm{NSC}$ & $=$ & Neural stem cells \\
\hline MWM & $=$ & Morris water maze \\
\hline $\mathrm{PD}$ & $=$ & Parkinson Disease \\
\hline PET & $=$ & Positron emission tomography \\
\hline PPAR- $\gamma$ & $=$ & $\begin{array}{l}\text { peroxisome proliferator-activated receptor- } \\
\gamma\end{array}$ \\
\hline PS1 & $=$ & Presilin 1 \\
\hline RMS & $=$ & Rostral migratory stream \\
\hline $\mathrm{SC}$ & $=$ & Stem Cells \\
\hline STM & $=$ & Short term memory \\
\hline SVZ & $=$ & Subventricular zone \\
\hline SYN & $=$ & Synaptophysin \\
\hline TBI & $=$ & Traumatic Brain Injury \\
\hline UCB-MSC & $=$ & $\begin{array}{l}\text { Umbilical cord blood derived mesenchy- } \\
\text { mal stem cells }\end{array}$ \\
\hline VEGF & $=$ & Vascular endothelial growth factor \\
\hline
\end{tabular}

\section{AUTHOR'S CONTRIBUTION}

$\mathrm{PB}$ and $\mathrm{AB}$ contributed in writing of manuscript. AA participated in the concept of review, it's designing and editing. DL has done concept designing, editing, rephrasing of manuscript and Maloney writing.

\section{CONFLICT OF INTEREST}

The author(s) confirm that this article content has no conflict of interest.

\section{ACKNOWLEDGEMENTS}

Declared none. 


\section{REFERENCES}

[1] Martin A, Maëlenn Guerchet, Gemma-Claire Ali, Yu-Tzu Wu, Matthew World Alzheimer Report 2015. Alzheimer's Disease International (2015)

[2] 2015 Alzheimer's disease facts and figures. Alzheimers Dement 11(3): 332-84 (2015). [3] ARSI. Alzheimer's and Related Disorders Society of India (ARDSI). (2010).

[4] Graeber MB, Kosel S, Egensperger R, Banati RB, Muller U, Bise $\mathrm{K}$, et al. Rediscovery of the case described by Alois Alzheimer in 1911: historical, histological and molecular genetic analysis. Neurogenetics 1(1): 73-80 (1997).

[5] Cummings JL, Back C. The cholinergic hypothesis of neuropsychiatric symptoms in Alzheimer's disease. Am J Geriatr Psychiatry. 6(2 Suppl 1): S64-78 (1998).

[6] Soto C. Unfolding the role of protein misfolding in neurodegenerative diseases. Nat Rev Neurosci 4(1): 49-60 (2003).

[7] Hardy JA, Higgins GA. Alzheimer's disease: the amyloid cascade hypothesis. Science (New York, NY) 256(5054): 184-5 (1992).

[8] Altman J. Autoradiographic investigation of cell proliferation in the brains of rats and cats. Anatomical Res 145: 573-91 (1963).

[9] Si YC, Li Q, Xie CE, Niu X, Xia XH, Yu CY. Chinese herbs and their active ingredients for activating xue (blood) promote the proliferation and differentiation of neural stem cells and mesenchymal stem cells. ChineseMed 9(1): 13 (2014).

[10] Saraf MK, Prabhakar S, Khanduja KL, Anand A. Bacopa monniera Attenuates Scopolamine-Induced Impairment of Spatial Memory in Mice. Evid Based Complement Alternat Med 2011: 236186 (2011).

[11] Prabhakar S, Saraf MK, Banik A, Anand A. Bacopa monniera selectively attenuates suppressed Superoxide dismutase activity in Diazepam induced amnesic mice. Ann Neurosci 18(1): 8-13 (2011).

[12] Saraf MK, Prabhakar S, Anand A. Neuroprotective effect of Bacopa monniera on ischemia induced brain injury. Pharmacol, BiochemBehav 97(2): 192-7 (2010).

[13] Singh T, Prabhakar S, Gupta A, Anand A. Recruitment of stem cells into the injured retina after laser injury. Stem Cells Develop 21(3): 448-54 (2012).

[14] Muthaian R, Minhas G, Anand A. Pathophysiology of stroke and stroke-induced retinal ischemia: emerging role of stem cells. J Cell Physiol 227(3): 1269-79 (2012).

[15] Blurton-Jones M, Kitazawa M, Martinez-Coria H, Castello NA, Muller FJ, Loring JF, et al. Neural stem cells improve cognition via BDNF in a transgenic model of Alzheimer disease. ProcNat AcadSci oUSA 106(32): 13594-9 (2009).

[16] Wilcock GK, Esiri MM. Plaques, tangles and dementia. A quantitative study. J Neurol Sci 56(2-3): 343-56 (1982).

[17] Vassar R, Bennett BD, Babu-Khan S, Kahn S, Mendiaz EA, Denis $\mathrm{P}$, et al. Beta-secretase cleavage of Alzheimer's amyloid precursor protein by the transmembrane aspartic protease BACE. Science (New York, NY) 286(5440): 735-41 (1999).

[18] Bie B, Wu J, Yang H, Xu JJ, Brown DL, Naguib M. Epigenetic suppression of neuroligin 1 underlies amyloid-induced memory deficiency. Nat Neurosci 17(2): 223-31 (2014).

[19] Davies P, Maloney AJ. Selective loss of central cholinergic neurons in Alzheimer's disease. Lancet 2(8000): 1403 (1976).

[20] Thies W, Bleiler L. 2013 Alzheimer's disease facts and figures. Alzheimers Dement 9(2): 208-45 (2013).

[21] Tai LM, Ghura S, Koster KP, Liakaite V, Maienschein-Cline M, Kanabar P, et al. APOE-modulated Abeta-induced neuroinflammation in Alzheimer's disease: current landscape, novel data, and future perspective. J Neurochem 133(4): 465-88 (2015).

[22] Wisniewski T, Frangione B. Apolipoprotein E: a pathological chaperone protein in patients with cerebral and systemic amyloid. Neurosci Lett 135(2): 235-8 (1992).

[23] Lahiri DK, Maloney B, Basha MR, Ge YW, Zawia NH. How and when environmental agents and dietary factors affect the course of Alzheimer's disease: the "LEARn" model (latent early-life associated regulation) may explain the triggering of $\mathrm{AD}$. CurrAlzheimer Res 4(2): 219-28 (2007).

[24] Banik A, Prabhakar S, Kalra J, Anand A. An enriched population of CD45, CD34 and CD117 stem cells in human umbilical cord blood for potential therapeutic regenerative strategies. CurrNeurovasc Res 11(4): 312-20 (2014).

[25] Jindal N, Minhas G, Prabhakar S, Anand A. Characterization of Lin-ve CD34 and CD117 cell population reveals an increased ex- pression in bone marrow derived stem cells. CurrNeurovasc Res 11(1): 68-74 (2014).

[26] Abburi C, Prabhakar S, Kalra J, Huria A, Anand A. Vascular endothelial growth factor (VEGF) induced proliferation of human fetal derived ciliary epithelium stem cells is mediated by jagged-N cadherin pathway. Curr Neurovasc Res 10(2): 93-102 (2013).

[27] Abburi C, Anand A. Ciliary epithelium: an underevaluated target for therapeutic regeneration. CritlRev Eukaryotic Gene Exp 22(2): 87-95(2012).

[28] Ray B, Chopra N, Long JM, Lahiri DK. Human primary mixed brain cultures: preparation, long-term maintenance, characterization and application to neuroscience research. MolBrain 7(1): 63 (2014).

[29] Yagi T, Ito D, Okada Y, Akamatsu W, Nihei Y, Yoshizaki T, et al. Modeling familial Alzheimer's disease with induced pluripotent stem cells. Hum Mol Genet 20(23): 4530-9 (2011).

[30] Kondo T, Asai M, Tsukita K, Kutoku Y, Ohsawa Y, Sunada Y, et al. Modeling Alzheimer's disease with iPSCs reveals stress phenotypes associated with intracellular Abeta and differential drug responsiveness. Cell Stem Cell 12(4): 487-96 (2013).

[31] Long JM, Ray B, Lahiri DK. MicroRNA-339-5p down-regulates protein expression of beta-site amyloid precursor protein-cleaving enzyme 1 (BACE1) in human primary brain cultures and is reduced in brain tissue specimens of Alzheimer disease subjects. J Biol Chemi 289(8): 5184-98 (2014).

[32] Cure S, Abrams K, Belger M, Dell'agnello G, Happich M. Systematic literature review and meta-analysis of diagnostic test accuracy in Alzheimer's disease and other dementia using autopsy as standard of truth. J AlzheimersDis 42(1): 169-82 (2014).

[33] Anand A, Banik A, Thakur K, Masters CL. The animal models of dementia and Alzheimer's disease for pre-clinical testing and clinical translation. Curr Alzheimer Res 9(9): 1010-29 (2012).

[34] Banik A, Anand APD. Preclinical non-human models to combat dementia. Ann Neurosci 20(1): 24-29 (2013).

[35] Monacelli F, Rosa G. Cholinesterase inhibitors: cardioprotection in Alzheimer's disease. J Alzheimers Dis 42(4): 1071-7 (2014).

[36] Birks J. Cholinesterase inhibitors for Alzheimer's disease. Cochrane Database Syst Rev (1): CD005593 (2006). [37] Ernfors $\mathrm{P}$, Wetmore C, Olson L, Persson H. Identification of cells in rat brain and peripheral tissues expressing mRNA for members of the nerve growth factor family. Neuron 5(4): 511-26 (1990).

[38] Prakash A, Kumar A. Role of nuclear receptor on regulation of BDNF and neuroinflammation in hippocampus of beta-amyloid animal model of Alzheimer's disease. Neurotox Res 25(4): 335-47 (2014).

[39] Seaberg RM, van der Kooy D. Stem and progenitor cells: the premature desertion of rigorous definitions. Trends Neurosci 26(3): 125-31 (2003)

[40] Tang J, Xu H, Fan X, Li D, Rancourt D, Zhou G, et al. Embryonic stem cell-derived neural precursor cells improve memory dysfunction in Abeta(1-40) injured rats. NeurosciRes 62(2): 86-96 (2008).

[41] Blurton-Jones M, Spencer B, Michael S, Castello NA, Agazaryan AA, Davis JL, et al. Neural stem cells genetically-modified to express neprilysin reduce pathology in Alzheimer transgenic models. Stem Cell research \& therapy 5(2): 46.(2014).

[42] ON K. Oral presentation titled "Peri-hippocampal stem cell transplantation rescues cognitive decline in Alzheimer's disease". Congress of Neurological Surgeons Annual Meeting in Boston, MA (2014).

[43] Jin K, Xie L, Mao X, Greenberg MB, Moore A, Peng B, et al. Effect of human neural precursor cell transplantation on endogenous neurogenesis after focal cerebral ischemia in the rat. Brain Res 1374: 56-62.(2011).

[44] Lee HJ, Lee JK, Lee H, Carter JE, Chang JW, Oh W, et al. Human umbilical cord blood-derived mesenchymal stem cells improve neuropathology and cognitive impairment in an Alzheimer's disease mouse model through modulation of neuroinflammation. NeurobiolAging 33(3): 588-602 (2012).

[45] Garcia KO, Ornellas FL, Martin PK, Patti CL, Mello LE, FrussaFilho R, et al. Therapeutic effects of the transplantation of VEGF overexpressing bone marrow mesenchymal stem cells in the hippocampus of murine model of Alzheimer's disease. Front Aging Neurosci 6: 30 (2014)

[46] Cherry JD, Olschowka JA, O'Banion MK. Neuroinflammation and M2 microglia: the good, the bad, and the inflamed. J Neuroinflamm 11: 98 (2014). 
[47] Yang H, Xie Z, Wei L, Yang H, Yang S, Zhu Z, et al. Human umbilical cord mesenchymal stem cell-derived neuron-like cells rescue memory deficits and reduce amyloid-beta deposition in an AbetaPP/PS1 transgenic mouse model. Stem Cell Res Therap 4(4): 76 (2013).

[48] Salem AM, Ahmed HH, Atta HM, Ghazy MA, Aglan HA. Potential of bone marrow mesenchymal stem cells in management of Alzheimer's disease in female rats. Cell Biol Intern 38(12): 1367-83 (2014).

[49] Oh SH, Kim HN, Park HJ, Shin JY, Lee PH. Mesenchymal stem cells increase hippocampal neurogenesis and neuronal differentiation by enhancing the Wnt signaling pathway in Alzheimer's disease model. Cell transplantation Cell Transplan 24(6): 1097-109 (2015).

[50] Zhang W, Wang GM, Wang PJ, Zhang Q, Sha SH. Effects of neural stem cells on synaptic proteins and memory in a mouse model of Alzheimer's disease. J Neurosci Res 92(2): 185-94 (2014).

[51] Prakash A, Medhi B, Chopra K. Granulocyte colony stimulating factor (GCSF) improves memory and neurobehavior in an amyloidbeta induced experimental model of Alzheimer's disease. Pharmacol, Biochem Behav 110: 46-57(2013).

[52] Shetty P, Thakur AM, Viswanathan C. Dopaminergic cells, derived from a high efficiency differentiation protocol from umbilical cord derived mesenchymal stem cells, alleviate symptoms in a Parkinson's disease rodent model. Cell Biol Intern 37(2): 167-80(2013).

[53] Chen S, Lewallen M, Xie T. Adhesion in the stem cell niche: biological roles and regulation. Development (Cambridge, England) 140(2): 255-65 (2013).

[54] Nori S, Okada Y, Nishimura S, Sasaki T, Itakura G, Kobayashi Y, et al. Long-term safety issues of iPSC-based cell therapy in a spinal cord injury model: oncogenic transformation with epithelialmesenchymal transition. Stem Cell rRep4(3): 360-73 (2015).

[55] Dlouhy BJ, Awe O, Rao RC, Kirby PA, Hitchon PW. Autograftderived spinal cord mass following olfactory mucosal cell transplantation in a spinal cord injury patient: Case report. J Neurosurg Spine 21(4): 618-22 (2014).

[56] Takahashi K, Yamanaka S. Induction of pluripotent stem cells from mouse embryonic and adult fibroblast cultures by defined factors. Cell 126(4): 663-76 (2006).

[57] Nakagawa M, Koyanagi M, Tanabe K, Takahashi K, Ichisaka T, Aoi $\mathrm{T}$, et al. Generation of induced pluripotent stem cells without Myc from mouse and human fibroblasts. Nat Biotechnol 26(1): 101-6 (2008).

[58] Jarocha D, Milczarek O, Kawecki Z, Wendrychowicz A, Kwiatkowski S, Majka M. Preliminary study of autologous bone marrow nucleated cells transplantation in children with spinal cord injury. Stem Cells Trans Med 3(3): 395-404 (2014).

[59] Mazzini L, Gelati M, Profico DC, Sgaravizzi G, Projetti Pensi M, Muzi G, et al. Human neural stem cell transplantation in ALS: initial results from a phase I trial. J Transl Med 13(1): 17 (2015).

[60] Song JH, Yu JT, Tan L. Brain-Derived Neurotrophic Factor in Alzheimer's Disease: Risk, Mechanisms, and Therapy. Mol Neurobiol 52(3): 1477-93 (2015).

[61] Dominguez G, Dagnas M, Decorte L, Vandesquille M, Belzung C, Beracochea D, et al. Rescuing prefrontal cAMP-CREB pathway reverses working memory deficits during withdrawal from prolonged alcohol exposure. Brain structure \& function (2014).

[62] Saraf MK, Anand A, Prabhakar S. Scopolamine induced amnesia is reversed by Bacopa monniera through participation of kinaseCREB pathway. Neurochem Res 35(2): 279-87 (2010).

[63] Hota SK, Barhwal K, Baitharu I, Prasad D, Singh SB, Ilavazhagan G. Bacopa monniera leaf extract ameliorates hypobaric hypoxia induced spatial memory impairment. Neurobiol Dis 34(1): 23-39 .(2009).

[64] Tota S, Goel R, Pachauri SD, Rajasekar N, Najmi AK, Hanif K, et al. Effect of angiotensin II on spatial memory, cerebral blood flow, cholinergic neurotransmission, and brain derived neurotrophic factor in rats. Psychopharmacology (Berl) 226(2): 357-69 (2013).

[65] Sharma N, Jadhav SP, Bapat SA. CREBBP re-arrangements affect protein function and lead to aberrant neuronal differentiation. Differentiation 79(4-5): 218-31 (2010).

[66] Raheja G, Gill KD. Altered cholinergic metabolism and muscarinic receptor linked second messenger pathways after chronic exposure to dichlorvos in rat brain. Toxicol IndustHealth 23(1): 25-37 (2007).
[67] Verma SK, Raheja G, Gill KD. Role of muscarinic signal transduction and CREB phosphorylation in dichlorvos-induced memory deficits in rats: an acetylcholine independent mechanism. Toxicology 256(3): 175-82 (2009).

[68] Yasuhara T, Hara K, Maki M, Xu L, Yu G, Ali MM, et al. Mannitol facilitates neurotrophic factor up-regulation and behavioural recovery in neonatal hypoxic-ischaemic rats with human umbilical cord blood grafts. J Cell Mol Med 14(4): 914-21 (2010).

[69] Fumagalli F, Racagni G, Riva MA. The expanding role of BDNF: a therapeutic target for Alzheimer's disease? Pharmacogenom J 6(1): 8-15 (2006).

[70] Siegel GJ, Chauhan NB. Neurotrophic factors in Alzheimer's and Parkinson's disease brain. Brain research Brain Res Rev 33(2-3): 199-227 (2000).

[71] Fahnestock M, Garzon D, Holsinger RM, Michalski B. Neurotrophic factors and Alzheimer's disease: are we focusing on the wrong molecule? J Neural Transm Supplemen (62): 241-52 (2002).

[72] Peng S, Wuu J, Mufson EJ, Fahnestock M. Precursor form of brain-derived neurotrophic factor and mature brain-derived neurotrophic factor are decreased in the pre-clinical stages of Alzheimer's disease. JNeurochem 93(6): 1412-21 (2005).

[73] Michalski B, Fahnestock M. Pro-brain-derived neurotrophic factor is decreased in parietal cortex in Alzheimer's disease. Brain research Molecular brain research 111(1-2): 148-54.(2003).

[74] Holsinger RM, Schnarr J, Henry P, Castelo VT, Fahnestock M. Quantitation of BDNF mRNA in human parietal cortex by competitive reverse transcription-polymerase chain reaction: decreased levels in Alzheimer's disease. Brain Res Mol Brain Res 76(2): 347 54 (2000).

[75] Kitiyanant N, Kitiyanant Y, Svendsen CN, Thangnipon W. BDNF-, IGF-1- and GDNF-secreting human neural progenitor cells rescue amyloid beta-induced toxicity in cultured rat septal neurons. NeurochemRes 37(1): 143-52 (2012).

[76] Arancibia S, Silhol M, Mouliere F, Meffre J, Hollinger I, Maurice $\mathrm{T}$, et al. Protective effect of BDNF against beta-amyloid induced neurotoxicity in vitro and in vivo in rats. NeurobiolDis 31(3): 31626 (2008).

[77] Holback S, Adlerz L, Iverfeldt K. Increased processing of APLP2 and APP with concomitant formation of APP intracellular domains in BDNF and retinoic acid-differentiated human neuroblastoma cells. J Neurochem95(4): 1059-68 (2005).

[78] Tong L, Balazs R, Thornton PL, Cotman CW. Beta-amyloid peptide at sublethal concentrations downregulates brain-derived neurotrophic factor functions in cultured cortical neurons. J Neurosci 24(30): 6799-809(2004).

[79] Zeng Y, Zhao D, Xie CW. Neurotrophins enhance CaMKII activity and rescue amyloid-beta-induced deficits in hippocampal synaptic plasticity. J Alzheimer's disease 21(3): 823-31.(2010).

[80] Li N, Liu GT. The novel squamosamide derivative FLZ enhances $\mathrm{BDNF} / \mathrm{TrkB} / \mathrm{CREB}$ signaling and inhibits neuronal apoptosis in APP/PS1 mice. Acta pharmacologica Sinica 31(3): 265-72 (2010).

[81] Lee Y, Kim J, Jang S, Oh S. Administration of Phytoceramide Enhances Memory and Upregulates the Expression of pCREB and BDNF in Hippocampus of Mice. Biomolecules \& therapeutics 21(3): 229-33 (2013).

[82] M. F. The effects of CREB-mediated BDNF expression on memory- and anxiety-related behaviours in the adult mouse. MSc Thesis (2012)

[83] Silva AJ, Kogan JH, Frankland PW, Kida S. CREB and memory. AnnRe v Neurosci 21: 127-48 (1998).

[84] Martin SJ, Grimwood PD, Morris RG. Synaptic plasticity and memory: an evaluation of the hypothesis. Ann Rev Neuroscience 23: 649-711 (2000).

[85] Jensen KF, Ohmstede CA, Fisher RS, Sahyoun N. Nuclear and axonal localization of $\mathrm{Ca} 2+/$ calmodulin-dependent protein kinase type $\mathrm{Gr}$ in rat cerebellar cortex. Proc Nat Acad Sci USA 88(7): 2850-3 (1991)

[86] Nakamura Y, Okuno S, Sato F, Fujisawa H. An immunohistochemical study of $\mathrm{Ca} 2+/$ calmodulin-dependent protein kinase IV in the rat central nervous system: light and electron microscopic observations. Neuroscience 68(1): 181-94 (1995).

[87] Matthews RP, Guthrie CR, Wailes LM, Zhao X, Means AR, McKnight GS. Calcium/calmodulin-dependent protein kinase types II and IV differentially regulate CREB-dependent gene expression. Mol Cell Biol 14(9): 6107-16 (1994). 
[88] Chrivia JC, Kwok RP, Lamb N, Hagiwara M, Montminy MR, Goodman RH. Phosphorylated CREB binds specifically to the nuclear protein CBP. Nature 365(6449): 855-9 (1993).

[89] Bito H, Deisseroth K, Tsien RW. CREB phosphorylation and dephosphorylation: a $\mathrm{Ca}(2+)$ - and stimulus duration-dependent switch for hippocampal gene expression. Cell 87(7): 1203-14 (1996).

[90] Suzuki A, Fukushima H, Mukawa T, Toyoda H, Wu LJ, Zhao MG, et al. Upregulation of CREB-mediated transcription enhances both short- and long-term memory. J Neurosci 31(24): 8786-802 (2011).

[91] Venkataramana NK, Kumar SK, Balaraju S, Radhakrishnan RC, Bansal A, Dixit A, et al. Open-labeled study of unilateral autologous bone-marrow-derived mesenchymal stem cell transplantation in Parkinson's disease. Transl Res 155(2): 62-70 (2010).

[92] Yin F, Tian ZM, Liu S, Zhao QJ, Wang RM, Shen L, et al. Transplantation of human retinal pigment epithelium cells in the treatment for Parkinson disease. CNS Neurosci Ther 18(12): 1012-20 (2012).

[93] Mancias-Guerra C, Marroquin-Escamilla AR, Gonzalez-Llano O, Villarreal-Martinez L, Jaime-Perez JC, Garcia-Rodriguez F, et al. Safety and tolerability of intrathecal delivery of autologous bone marrow nucleated cells in children with cerebral palsy: an openlabel phase I trial. Cytotherapy 16(6): 810-20 (2014).

[94] http://clinicaltrials.gov/ct2/show/NCT01297218. The Safety and The Efficacy Evaluation of NEUROSTEM $\mathbb{R}-\mathrm{AD}$ in Patients With Alzheimer's Disease. ClinicalTrialsgov Identifier: NCT01297218.

[95] https://clinicaltrials.gov/ct2/show/NCT01547689. Safety and Efficiency of Umbilical Cord-derived Mesenchymal Stem Cells(UCMSC) in Patients With Alzheimer's Disease (SEMAD). Clinical Trialsgov Identifier: NCT01547689May (2014).

[96] https://clinicaltrials.gov/ct2/show/NCT02054208. Safety and Exploratory Efficacy Study of NEUROSTEM ${ }^{\circledR}$ Versus Placebo in Patients With Alzheimer's Disease. clinicaltrialsgov identifier: nct02054208February (2014).

[97] Banik A, Brown RE, Bamburg J, Lahiri DK, Khurana D, Friedland RP, et al. Translation of Pre-Clinical Studies into Successful Clinical Trials for Alzheimer's Disease: What are the Roadblocks and How Can They Be Overcome?1. J Alzheimers Dis 47(4): 815-43 (2015).

[98] Zhang R, Liu Y, Yan K, Chen L, Chen XR, Li P, et al. Antiinflammatory and immunomodulatory mechanisms of mesenchymal stem cell transplantation in experimental traumatic brain injury. J Neuroinflamm 10(1): 106 (2013).

[99] Wen SR, Qi HP, Ren YJ, Liu GJ, Gong FC, Zhong H, et al. Expression of deltaNp73 in hippocampus of APP/PS1 transgenic mice following GFP-BMSCs transplantation. NeurolRes 33(10): 110914 (2011).

[100] Marei HE, Farag A, Althani A, Afifi N, A AE, Lashen S, et al. Human Olfactory Bulb Neural Stem Cells expressing hNGF Re- store Cognitive Deficit in Alzheimer's Disease Rat Model.J Cell Physiol. ;230(1): 116-30 (2015)..

[101] Zhang W, Wang PJ, Gu GJ, Li MH, Gao XL. [Effects of neural stem cells transplanted into an animal model of Alzheimer disease on Abeta plaques]. Zhonghua yi xue za zhi 93(45): 3636-9 (2013).

[102] Yun HM, Kim HS, Park KR, Shin JM, Kang AR, il Lee K, et al. Placenta-derived mesenchymal stem cells improve memory dysfunction in an Abeta1-42-infused mouse model of Alzheimer's disease Cell Death Dis 4: e958 (2013).

[103] Shin JY, Park HJ, Kim HN, Oh SH, Bae JS, Ha HJ, et al. Mesenchymal stem cells enhance autophagy and increase beta-amyloid clearance in Alzheimer disease models. Autophagy 10(1): 32-44 (2014).

[104] Yang H, Yang H, Xie Z, Wei L, Bi J. Systemic transplantation of human umbilical cord derived mesenchymal stem cells-educated T regulatory cells improved the impaired cognition in AbetaPPswe/PS1dE9 transgenic mice. PloS one 8(7): e69129 (2013).

[105] Kim KS, Kim HS, Park JM, Kim HW, Park MK, Lee HS, et al. Long-term immunomodulatory effect of amniotic stem cells in an Alzheimer's disease model. NeurobiolAging 34(10): 2408-20 (2013).

[106] Kim S, Chang KA, Kim J, Park HG, Ra JC, Kim HS, et al. The preventive and therapeutic effects of intravenous human adiposederived stem cells in Alzheimer's disease mice. PloS one 7(9): e45757 (2012)

[107] Bae JS, Jin HK, Lee JK, Richardson JC, Carter JE. Bone marrowderived mesenchymal stem cells contribute to the reduction of amyloid-beta deposits and the improvement of synaptic transmission in a mouse model of pre-dementia Alzheimer's disease. Curr Alzheimer Res 10(5): 524-31 (2013).

[108] Kim JY, Kim DH, Kim JH, Lee D, Jeon HB, Kwon SJ, et al. Soluble intracellular adhesion molecule-1 secreted by human umbilical cord blood-derived mesenchymal stem cell reduces amyloid-beta plaques. Cell Death Differen 19(4): 680-91 (2012).

[109] Esmaeilzade B, Nobakht M, Joghataei MT, Rahbar Roshandel N, Rasouli H, Samadi Kuchaksaraei A, et al. Delivery of epiderma neural crest stem cells (EPI-NCSC) to hippocamp in Alzheimer's disease rat model. Iranian Biomed J16(1): 1-9 (2012).

[110] Park D, Joo SS, Kim TK, Lee SH, Kang H, Lee HJ, et al. Human neural stem cells overexpressing choline acetyltransferase restore cognitive function of kainic acid-induced learning and memory deficit animals. Cell Transp 21(1): 365-71 (2012).

[111] Nikolic WV, Hou H, Town T, Zhu Y, Giunta B, Sanberg CD, et al. Peripherally administered human umbilical cord blood cells reduce parenchymal and vascular beta-amyloid deposits in Alzheimer mice. Stem Cells Develop 17(3): 423-39 (2008). 